\title{
ANALISIS KANDUNGAN MIKROPLASTIK PADA USUS IKAN TUNA MATA BESAR (Thunnus obesus) YANG DIDARATKAN DI PELABUHAN IKAN WAKATOBI
}

\section{MICROPLASTIC ANALYSIS OF BIG EYES TUNA (Thunnus obesus) LANDED AT THE PORT OF FISH IN WAKATOBI}

\author{
Wa Ode Nur Asma La Dia ${ }^{1}$, Wayan Kantun ${ }^{2}$, \& Arnold Kabangnga** \\ ${ }^{1}$ Departemen Teknologi Hasil Perairan, Fakultas Perikanan dan Ilmu Kelautan, \\ IPB University, Bogor, 16680, Indonesia \\ ${ }^{2}$ Departemen Sumberdaya Akuatik, Institut Teknologi dan Bisnis Maritim Balik Diwa, \\ Makassar, 90245, Indonesia \\ ${ }^{3}$ Departemen Pemanfaatan Sumberdaya Perairan, Institut Teknologi dan Bisnis Maritim Balik \\ Diwa, Makassar, 90245, Indonesia \\ *E-mail: arnoldkabangnga@gmail.com
}

\begin{abstract}
Plastic pollution has an effect on marine waters and limited information about the impact on the digestive tracts of migratory fish. Therefore, this study aims to analyze the content of microplastics in the digestive system of fish that are located in the intestines and identify the type of microplastic polymers in the meat of big-eyes tuna fish landed in the port of Wakatobi fish. The research was conducted from March to July 2020 in Wakatobi Regency. The process of identifying the microplastic content in the intestines of bigeyes tuna was carried out in 4 stage, namely (1) fish disscetion, (2) density separation, (3) removal of organic compounds, (4) visual observation. Identification of the type of microplastic polymers in meat of bigeyes tuna was analyzed using fourier transform infrared (FTIR). The results showed that there are microplastics in the intestines of big-eyes tuna fish numbering twelve particles with microplastic types in the form of blue, brown and red fibers. The size of microplastic which found was 0.701-4.305 $\mathrm{mm}$. The results of FTIR analysis on fish meat showed polyethylene compounds marked by the presence of $C=O$ stretch bonds.
\end{abstract}

Keywords: FTIR, microplastic, Thunnus obesus, Wakatobi

\begin{abstract}
ABSTRAK
Pencemaran plastik memiliki efek terhadap perairan laut dan terbatasnya informasi mengenai dampak terhadap saluran pencernaan ikan migrasi. Oleh karena itu, penelitian ini bertujuan untuk menganalisis kandungan mikroplastik pada sistem pencernaan ikan yang terletak pada bagian usus dan identifikasi jenis polimer mikroplastik pada daging ikan tuna mata besar yang didaratkan di pelabuhan ikan Wakatobi. Penelitian ini dilaksanakan pada bulan Maret sampai Juli 2020 di Kabupaten Wakatobi. Proses identifikasi kandungan mikroplastik pada usus ikan tuna mata besar dilakukan dengan 4 tahap, yaitu (1) tahap pembedahan ikan, (2) pemisahan densitas, (3) penghilangan senyawa organik, (4) pengamatan visual. Identifikasi jenis polimer mikroplastik pada daging ikan tuna mata besar dianalisis menggunakan fourrier trasform infrared (FTIR). Hasil penelitian menunjukkan bahwa terdapat mikroplastik pada usus ikan tuna mata besar berjumlah dua belas partikel dengan tipe mikroplastik berupa fiber berwarna biru, cokelat dan merah. Ukuran mikroplastik yang ditemukan yaitu 0,7014,305 mm. Hasil analisis FTIR pada daging ikan menunjukkan senyawa polyethylene ditandai dengan adanya ikatan $\mathrm{C}=\mathrm{O}$ stretch.
\end{abstract}

Kata kunci: FTIR, mikroplastik, Thunnus obesus, Wakatobi

\section{PENDAHULUAN}

Mikroplastik merupakan plastik yang berukuran kecil $(<5 \mathrm{~mm})$ yang umumnya berasal dari hasil degradasi plastik-plastik yang berukuran besar (Hidalgo-Ruz et al., 2012; GESAMP, 2015). Mikroplastik dapat memasuki perairan laut secara langsung 
dalam bentuk mikroplastik primer maupun tidak langsung dalam bentuk sekunder. Mikroplastik primer merupakan plastik yang sengaja dibuat berukuran kecil misalnya sebagai pelet resin, termoplastik, scrubber dalam produk perawatan, industrial abrasives, exfolian, dan plastik yang digunakan dalam rotomilling. Mikroplastik sekunder merupakan hasil dari fragmentasi produk plastik yang lebih besar menjadi potongan yang berukuran kecil (Stevenson, 2011). Sumber sekunder inilah yang menjadi sumber utama yang menyebabkan keberadaan mikroplastik dilaut yang mencemari lingkungan seperti mikroplastik jenis fragmen, fiber dan juga film (Andrady, 2011; Hidalgo-Ruz et al., 2012).

Mikroplastik tersebar luas di perairan laut yang berada pada permukaan, dasar laut, maupun pantai serta pada sedimen di seluruh dunia (Claessens et al., 2011; Lusher et al., 2013). Keberadaan mikroplastik di perairan karena mengalami degradasi, fragmentasi dan pelepasan bahan perekat sehingga terjadi perubahan densitas (GESAMP, 2015). Ukuran mikroplastik yang kecil menjadi peluang besar tercerna oleh berbagai organisme laut secara tidak sengaja. Ukuran yang kecil memungkinkan mereka melewati hambatan biologis, untuk menembus jaringan dan menumpuk pada organ (Von moos et al., 2012). Beberapa penelitian telah mengidentifikasi adanya keberadaan mikroplastik pada tubuh hewan laut. Mikroplastik ditemukan rata-rata 2,1 partikel mikroplastik pada sistem pencernaan ikan epipelagik di Pasifik Utara (Boerger et al., 2010). Rochman et al. (2015) juga dalam penelitiannya menemukan ikan yang dijual di pasar California dan Makassar (Indonesia) terdapat kandungan mikroplastik. Selain pada ikan, mikroplastik juga sudah ditemukan pada bivalvia dari spesies Mytilus endulis dari pantai China, yaitu 0,9-4,6 item/g dan 1,5-7,6 item/individu (Li et al., 2016). Mikroplastik juga ditemukan pada kerang-kerangan di perairan Brazil (Santana et al., 2016). Jalur utama tertelannya mikroplastik adalah karena kesalahan dalam memilih mangsa atau menganggap bahwa mikroplastik merupakan mangsanya (Lusher et al., 2013; Boerger et al., 2014). Pada ikan, organ tubuh yang dapat terpapar mikroplastik adalah insang, saluran pencernaan maupun lambung. Pernyataan ini didukung dengan beberapa hasil penelitian yang menyebutkan bahwa keberadaan mikroplastik pada saluran pencernaan ikan dianggap sebagai tempat terakumulasinya mikroplastik (Murphy et al., 2017; Baalkhuyur et al., 2018; Giani et al., 2019; Savoca et al., 2019).

Mikroplastik memberikan dampak negatif bagi biota laut karena adanya senyawa kimia yang terkandung dalam plastik maupun senyawa toksik lainnya yang menempel pada mikroplastik. Sementara bahaya fisik dari mikroplastik yang berukuran kecil memungkinkan terjadinya translokasi mikroplastik ke organ-organ hewan atau organisme yang menelan mikroplastik (Vandermeersch et al., 2015). Dampak partikel mikroplastik yang tertelan meliputi tiga proses: (1) merusak dan memblokir secara fisik saluran pencernaan, (2) pelarut bahan kimia komponen plastik maupun kontaminan yang menempel pada permukaan plastik ke dalam organisme setelah proses pencernaan, dan (3) akumulasi bahan kimia yang diserap oleh organisme (Teuten et al., 2016). Partikel plastik yang terakumulasi banyak dalam tubuh ikan dapat menghambat saluran pencernaan ikan (Browne et al., 2013), mengganggu proses-proses pencernaan atau menghalangi proses penyerapan (Wright et al., 2013) dan dapat memfasilitasi transportasi kontaminasi kimia (Hirai et al., 2011).

Mikroplastik juga telah banyak ditemukan pada objek wisata pantai yang selalu dikunjungi oleh wisatawan (Cole et al., 2011). Hal ini terjadi karena adanya pergerakan mikroplastik yang dipengaruhi oleh faktor-faktor oseanografi seperti gelombang dan arus (Iwasaki et al., 2017). Kabupaten Wakatobi merupakan salah satu destinasi pariwisata berbasis perikanan dan kelautan 
yang cukup rentan terhadap keberadaan mikroplastik. Potensi pengembangan ekonomi kelautan Wakatobi sangat besar khususnya pada sektor perikanan tangkap. Berdasarkan data dari Dinas Kelautan dan Perikanan (DKP) Kabupaten Wakatobi, produksi perikanan tangkap mencapat 18,855 ton/tahun yang didominasi oleh ikan pelagis, yaitu ikan tuna dengan produksi 401 ton/tahun. Oleh karena itu, penelitian ini dilaksanakan untuk mengungkap keberadaan mikroplastik pada usus ikan tuna mata besar dan identifikasi jenis polimer mikroplastik pada daging ikan tuna mata besar yang didaratkan di Pelabuhan ikan Wakatobi.

\section{METODE PENELITIAN}

\subsection{Materi Penelitian}

Penelitian ini dilaksanakan pada bulan Maret sampai Juli 2020, dengan lokasi pengambilan sampel pada daerah Mola/Bajo Kabupaten Wakatobi. Analisis kandungan mikroplastik dilakukan di Laboratorium Produktivitas dan Kualitas Perairan, Fakultas Kelautan dan Perikanan, Universitas Hasanuddin dan analisis polimer mikroplastik dilakukan di Laboratorium Kimia Terpadu, Universitas Hasanuddin. Sampel ikan tuna mata besar diambil di Pendaratan ikan di Desa Mola/Bajo Kabupaten Wakatobi. Pengambilan dilakukan sebanyak 3 (tiga) kali yang dilakukan 1 (satu) minggu sekali, setiap seminggu diambil sebanyak 3 (tiga) ekor ikan tuna mata besar sehingga total keseluruhan ikan berjumlah 9 ekor, identifikasi mikroplastik menggunakan metode yang telah dikembangkan oleh Rochman et al. (2015). Sampel ikan kemudian didokumentasi dan diidentifikasi jenis spesiesnya. Proses identifikasi spesies ikan berdasarkan buku identifikasi ikan madidihang dan tuna mata besar (Itano, 2004).

Identifikasi kandungan mikroplastik pada usus ikan tuna mata besar dilakukan dengan 4 tahap, yaitu (1) tahap pembedahan ikan, (2) pemisahan densitas, (3) penghilangan senyawa organik, (4) pengamatan visual. Sampel ikan dilakukan pembedahan menggunakan dissecting set kemudian sampel saluran pencernaan ikan disimpan pada pada glassware bening (duran) ukuran $250 \mathrm{ml}$ dan disimpan pada freezer. Proses pemisahan densitas (density separation) dengan menambhakan $\mathrm{NaCl}$ jenuh pada sampel kemudian dilakukan penyaringan pada mesh $0,3 \mathrm{~mm}$ yang dilanjukan dengan proses pengeringan pada oven dengan suhu $90{ }^{\circ} \mathrm{C}$ selama semalam. Sampel kering kemudian dilakukan penghancuran senyawa organik dengan menambahkan $\mathrm{KOH}(10 \%)$ dan direndam selama 3 minggu pada suhu ruang. $\mathrm{KOH}$ merupakan senyawa basa kuat yang efisien dalam proses reduksi saluran pencernaan ikan (organik) yang recovery rate yang dihasilkan tinggi jika dibandingkan dengan larutan lainnya dan konsentrasi $\mathrm{KOH}$ $10 \%$ menghasilkan sisa jaringan halus paling sedikit 0,225 $\pm 0,009 \%$ (Karami et al., 2017). Kemudian dilakukan pemisahan endapan organik dengan partikel mikroplastik yang disaring menggunakan kain saring dengan ukuran mesh sebesar $120 \mu \mathrm{m}$ (Yudhantari et al., 2019). Sampel yang telah tersaring, dibilas dengan aquades lalu dipindahkan ke kertas saring whatman yang berukuran 11 $\mu \mathrm{m}$ dan dilapisi dengan alumunium foil untuk dilakukan pengamatan menggunakan mikroskop. Kertas whatman yang terdapat sampel dipindahkan ke cawan petri untuk memudahkan selama proses identifikasi.

Identifikasi mikroplastik menggunakan mikroskop Olympus CX21 dengan perbesaran 4x/0.10. Proses dokumentasi menggunakan perangkat lunak OptiLab dan untuk penentuan ukuran mikroplastik menggunakan perangkat lunak Image Raster. Proses identifikasi dilakukan dengan panduan Hidalgo-Ruz (2012) mengenai identifikasi partikel mikroplastik, dari bentuk, warna, ukuran serta jumlah partikel mikroplastik dan dikolaborasi dengan panduan Virsek et al. (2016). 


\subsection{Identifikasi Polimer Mikroplastik pada Daging Ikan}

Identifikasi jenis polimer mikroplastik menggunakan metode fourrier transform infrared (FTIR) untuk menganalisis berdasarkan pengukuran intensitas infra-red terhadap panjang gelombang. Metode FTIR juga dapat mendeteksi karakteristik vibrasi kelompok fungsi dari senyawa pada sampel dan berfungsi dalam memberikan informasi seperti penentuan struktur molekul pada polimer, identifikasi senyawa berikatan kovalen, untuk mengetahui kemurnian bahan, serta mengetahui gugus fungsi dari molekul (Aspi et al., 2013). Sampel daging ikan tuna mata besar terlebih dahulu dicuci menggunakan aquades untuk menghilangkan kontaminasi pada permukaan daging ikan, kemudian sampel daging ikan tuna mata besar dikeringkan menggunakan oven. Sampel kering diambil sebanyak $10 \mathrm{~g}$ dan ditambahkan $\mathrm{KBr}$ (kalium bromida) kemudian digerus sampai halus dan homogen. Kemudian dilakukan pencetakan pellet lalu dimasukkan dalam alat FTIR dan dilakukan pembacaan sprektrum. Spektrum ini nantinya dapat digunakan pada identifikasi jenis polimer plastik berdasarkan referensi Baalkhuyur et al. (2018).

\section{HASIL DAN PEMBAHASAN}

\subsection{Mikroplastik pada Usus Ikan}

Jenis ikan yang dianalisis pada penelitian ini adalah ikan tuna mata besar (Thunnus obesus). Ikan tuna mata besar (Thunnus obesus) yang diperoleh diklasifikasikan menjadi 2 ukuran yakni larva (12,9 $\mathrm{cm}-13,9 \mathrm{~cm})$ dan ukuran juvenil $(37,7 \mathrm{~cm}-$ $60,2 \mathrm{~cm})$. Pengelompokkan ini berdasarkan pengelompokan menurut Simonds \& Page (2006) yang mengklasifikasi ukuran ikan tuna sirip kuning dan ikan tuna mata besar yakni ukuran $<20 \mathrm{~cm}$ digolongkan sebagai telur atau larva, ukuran $20-75 \mathrm{~cm}$ sebagai juvenil, ukuran $76-110 \mathrm{~cm}$ sebagai subdewasa dan ukuran $>110 \mathrm{~cm}$ sebagai ukuran dewasa.
Hasil pengamatan menunjukkan bahwa terdapat dua sampel ikan yang ditemukan mengandung mikroplastik sebanyak 12 partikel/individu pada ikan ukuran juvenil dengan tipe mikroplastik fiber (Gambar 1). Peluang ditemukannya mikroplastik pada ikan tuna mata besar (Thunnus obesus) ukuran juvenil dipengaruhi karna semakin banyaknya kebutuhan makanan yang harus dimakan oleh ikan tersebut. Sejalan dengan pernyataan Kantun \& Mallawa (2016) bahwa semakin besar ikan maka kebutuhan makanan dan daya tampung makanan juga semakin besar.

Mikroplastik tipe fiber atau filamen berpeluang ditemukan pada sampel ikan tuna mata besar karena daerah pendaratan ikan tuna mata besar (Thunnus obesus) yaitu Desa Mola/Bajo, berada di daerah pemukiman penduduk yang cukup padat, bermukim di atas perairan laut sehingga rata rata penduduknya bermata pencaharian sebagai nelayan, di Daerah Mola/Bajo pula terdapat aktivitas penyebrangan dan pusat perbelanjaan (pasar) sehingga dari aktivitas masyarakat di Desa Mola/Bajo pun tentunya menghasilkan limbah rumah tangga. Sarana pengelolaan sampah plastik di Desa Mola/Bajo pun bisa dikatakan belum tersedia sehingga biasanya penanganan sampah dilakukan dengan cara pembakaran bahkan terkadang sampah plastik pun berakhir ke laut. Sampah makro yang masuk badan air kemudian akan terurai menjadi puing-puing plastik kecil yang disebut dengan mikroplastik. Selain itu juga adanya mikroplastik tipe fiber diprediksi berasal dari alat tangkap nelayan. Alat tangkap yang umumnya berasal dari tali yang merupakan jenis fiber akan mengalami degradasi (Nor \& Obbard, 2014).

Beberapa penelitian menunjukkan tipe mikroplastik banyak ditemukan pada ikan pelagis dan demersal adalah fiber (Rummel et al., 2016). Lusher et al. (2013) juga menemukan tipe fiber mendominasi sebanyak $68,3 \%$ dari tipe mikroplastik lainnya. Philips \& Bonner (2015) pada 
penelitiannya juga menemukan jenis mikroplastik fiber lebih tinggi dibandingkan dengan tipe lainnya pada ikan-ikan yang ditemukan di Teluk Meksiko. Anastasopoulou et al. (2013) juga menemukan bahwa kelompok ikan pelagis cenderung menelan mikroplastik tipe fiber.

Berdasarkan hasil pengamatan mikroplastik tipe fiber atau filamen diidentifikasi bahwa warna mikroplastik tipe fiber atau filamen menunjukkan warna yang beragam yaitu warna biru, cokelat dan merah (Gambar 2 dan Tabel 1). Gambar 2 dan Tabel 1 memperlihatkan bahwa warna mikroplastik pada jenis fiber atau filamen didominasi oleh warna biru sebanyak 7 mikroplastik (partikel/ individu) warna merah sebanyak 3 mikroplastik (partikel/individu) dan terakhir warna cokelat sebanyak 2 mikroplastik (partikel/individu). Penelitian Ory et al. (2018) menemukan mikroplastik pada saluran pencernaan ikan dengan berbagai macam warna mengindikasikan bahwa ikan tidak menelan mikroplastik berdasarkan warna. Boerger et al. (2010) juga menemukan mikroplastik pada ikan pelagis di North Pasific Gyre bukan bergantung pada warna karena komposisi warna yang tertelan sama dengan komposisi warna mikroplastik di perairan.

Berdasarkan ukurannya, ukuran mikroplastik yang ditemukan pada ikan tuna mata besar (Thunnus obesus) didominasi oleh jenis fiber pada ukuran 0,701-4,305 mm (Tabel 1). Mikroplastik ditemukan pada usus ikan tuna mata besar (Thunnus obesus) berukuran juvenil. Hasil penelitian $\mathrm{Su}$ et al. (2019) menemukan fiber dengan ukuran yang lebih besar (> $1 \mathrm{~mm})$ pada saluran pencernaan ikan. Rummel et al. (2016) juga menemukan ukuran fiber 150-3000 $\mu \mathrm{m}$ dalam ikan pelagis dan demersal.

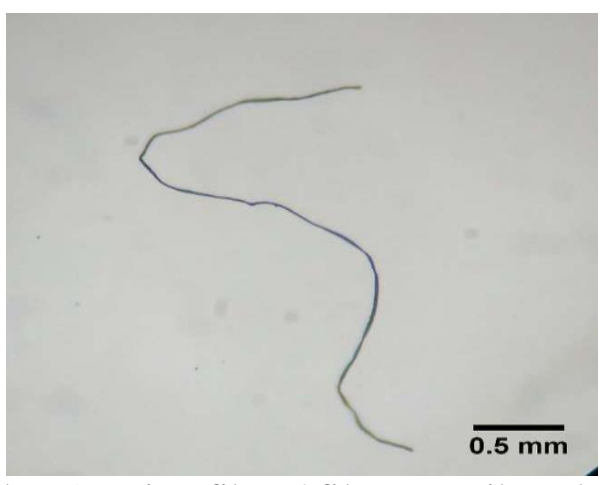

Gambar 1. Tipe fiber / filamen mikroplastik yang ditemukan dalam penelitian.

Tabel 1. Warna dan ukuran mikroplastik tipe fiber / filamen

\begin{tabular}{lc}
\hline Warna & Ukuran $(\mathrm{mm})$ \\
\hline Biru & 4,305 \\
Biru & 0,987 \\
Biru & 1,790 \\
Merah & 1,252 \\
Biru & 1,085 \\
Merah & 1,518 \\
Cokelat & 3,184 \\
Cokelat & 1,388 \\
Biru & 0,701 \\
Biru & 1,659 \\
Merah & 0,731 \\
Biru & 3,751 \\
\hline
\end{tabular}

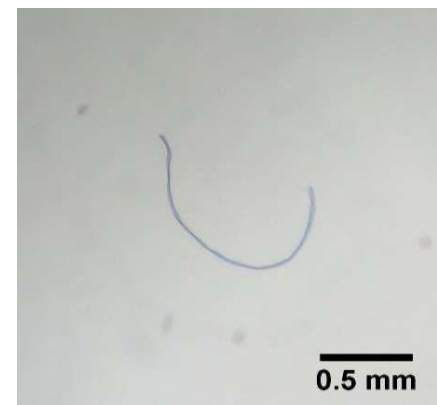

(a) Biru

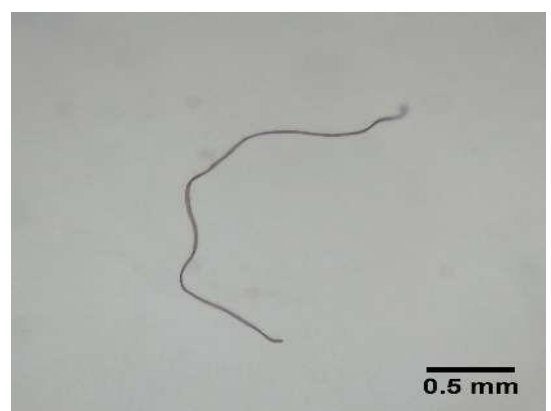

(b) Cokelat

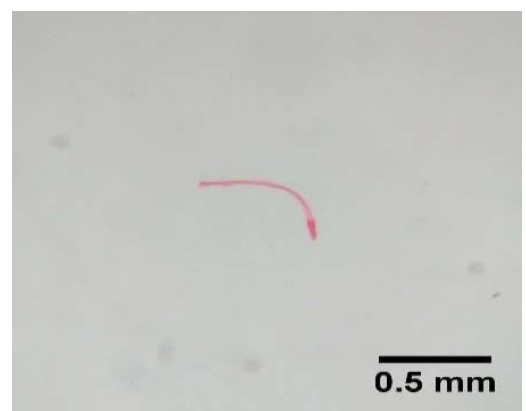

(c) Merah

Gambar 2. Tipe mikroplastik fiber / filamen: (a) biru. (b) cokelat, (c) merah. 


\subsection{Analisis FTIR pada Daging Ikan}

Hasil pembacaan FTIR daging ikan

tuna mata besar (Thunnus obesus) menunjukkan terdapat beberapa puncak panjang gelombang yang menunjukkan ikatan suatu senyawa (Tabel 2 dan Gambar 3). Hasil interpretasi FTIR dilakukan berdasarkan panduan Nandiyanto et al. (2019). Hasil Interpretasi menunjukkan bahwa pada sampel terdapat peak utama yang menunjukkan polymer Polyethylene (PE). Senyawa Polyethylene (PE) ditunjukkan dengan adanya $\mathrm{C}=\mathrm{O}$ stretch $\left(1713 \mathrm{~cm}^{-1}\right), \mathrm{C}-\mathrm{O}$ stretch $\left(1241 \mathrm{~cm}^{-1}\right), \mathrm{C}-\mathrm{O}$ stretch $\left(1094 \mathrm{~cm}^{-1}\right)$, Aromatic $\mathrm{CH}$ out ofplane bend $\left(720 \mathrm{~cm}^{-1}\right), \mathrm{C}-\mathrm{H}$ stretch $(2915$ $\left.\mathrm{cm}^{-1}\right), \mathrm{C}-\mathrm{H}$ stretch $\left(2845 \mathrm{~cm}^{-1}\right), \mathrm{CH}_{2}$ bend $\left(1472 \mathrm{~cm}^{-1}, 1462 \mathrm{~cm}^{-1}\right), \mathrm{CH}_{2}$ rock $\left(730 \mathrm{~cm}^{-1}\right.$, $717 \mathrm{~cm}^{-1}$ ) (Verleye et al., 2001; Noda et al., 2007; Asensio et al., 2009). Polyethylene (PE) adalah termoplastik yang digunakan secara luas oleh konsumen produk sebagai kantong plastik. Hasil interpretasi FTIR daging ikan tuna mata besar disajikan pada Tabel 2 berikut.

Tabel 2. Hasil interpretasi gugus fungsi pada daging ikan (Thunnus obesus).

\begin{tabular}{ccc}
\hline Panjang gelombang $\left(\mathrm{cm}^{-1}\right)$ & Ikatan & Polyethylene $(\mathrm{PE})$ \\
\hline $1725-17000$ & $\mathrm{C}=\mathrm{O}$ stretch \\
$1270-1230$ & $\mathrm{C}-\mathrm{O}$ stretch \\
$1140-1070$ & $\mathrm{C}-\mathrm{O}$ stretch \\
$900-670$ & Aromatic $\mathrm{CH}$ out-of- \\
& plane bend \\
$2935-2915$ & $\mathrm{C}-\mathrm{H}$ stretch \\
$2850-2815$ & $\mathrm{C}-\mathrm{H}$ stretch \\
$1485-1445$ & $\mathrm{CH}_{2}$ bend \\
$750-720$ & $\mathrm{CH}_{2}$ rock & \\
&
\end{tabular}

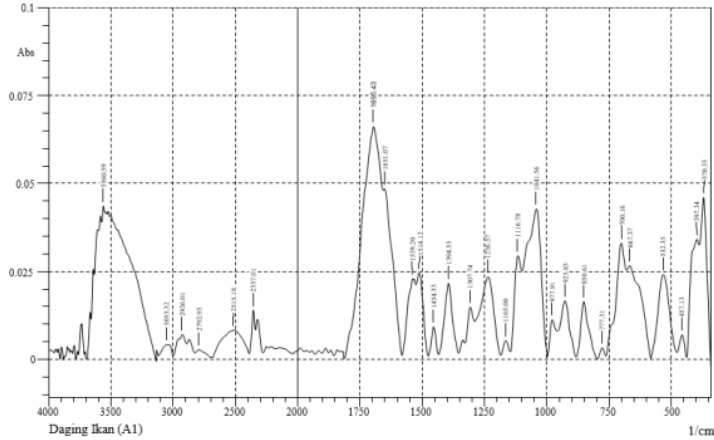

(Daging A1)

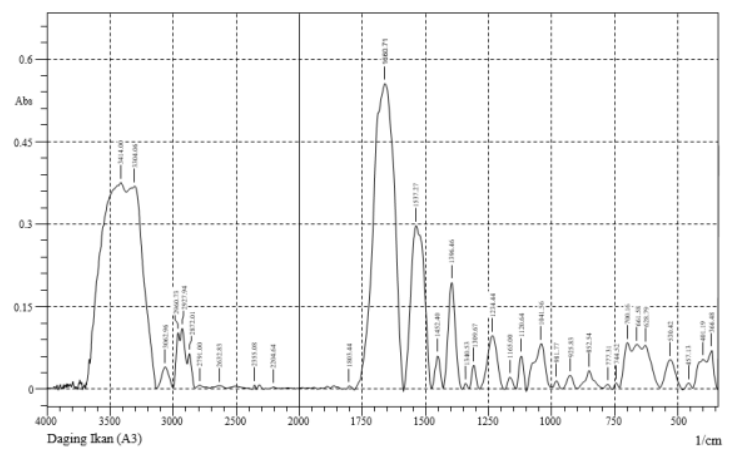

(Daging A3)

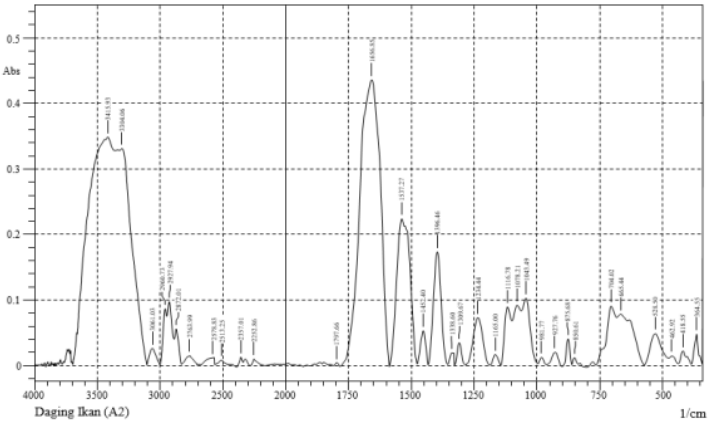

(Daging A2)

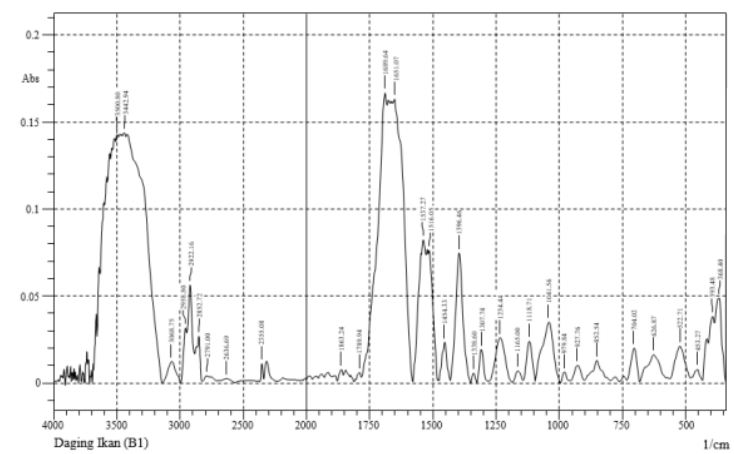

(Daging B1) 


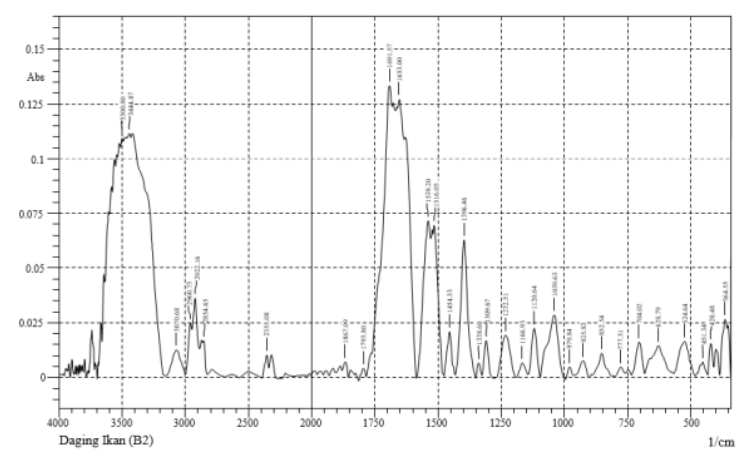

(Daging B2)

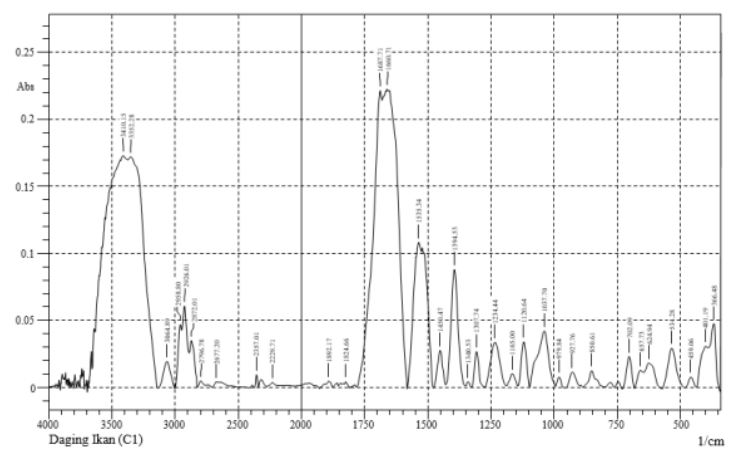

(Daging C1)

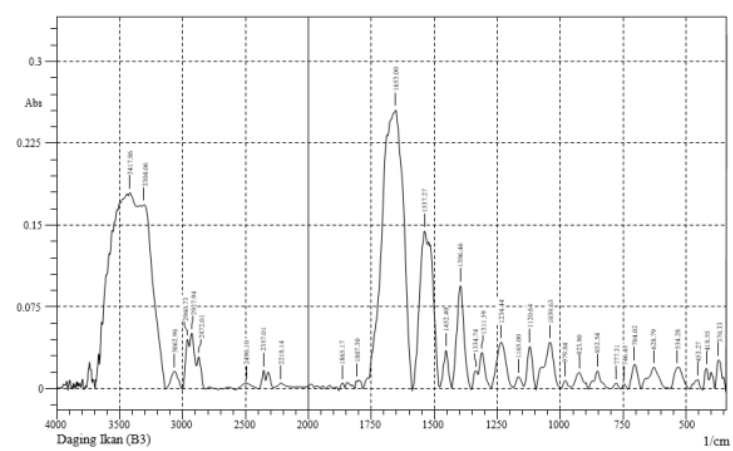

(Daging B3)



(Daging C2)

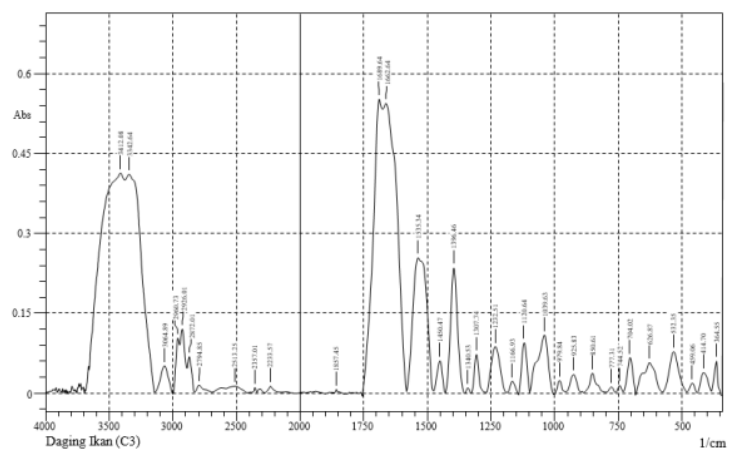

(Daging C3)

Gambar 3. Hasil identifikasi FTIR pada daging ikan (Thunnus obesus); $\mathrm{x}=$ panjang gelombang, $\mathrm{y}=$ intensitas.

\section{KESIMPULAN}

Ikan tuna mata besar (Thunnus obesus) yang didaratkan di pelabuhan ikan Wakatobi ditemukan mikroplastik tipe fiber/filamen pada saluran pencernaan (usus) juvenil ikan tuna mata besar, dengan komposisi ukuran dan warna yang bervariasi. Hasil analisis FTIR (fourrier transform infrared) pada daging ikan menunjukkan adanya senyawa polyethylene.

\section{UCAPAN TERIMA KASIH}

Terima kasih kepada Dinas Kelautan dan Perikanan Kabupaten Wakatobi, Dosen dan Para Staf Institut Teknologi dan Bisnis Maritim Balik Diwa Makassar. Ucapan terima kasih juga disampaikan kepada para reviewer yang banyak memberikan saran dan komentar untuk perbaikan naskah ini. 


\section{DAFTAR PUSTAKA}

Anastasopoulou, A., C. Mytilineou, C.J. Smith, \& K.N. Papadopoulou. 2013. Plastic debris ingested by deep-water fish of the Ionian Sea (Eastern Mediterranean). Deep-Sea Research Part I: Oceanographic Research Papers, 74: 11-13. https://doi.org/10.1016/j.dsr.2012.12. 008

Asensio, R.C., M.S.A. Moya, J.M.D.L Roja, \& M. Gomez. 2009. Analytical characterization of polymers used in conservation and restoration by ATRFTIR spectroscopy. Analytical and Bioanalytical Chemistry, 395(7): 2081-2096.

https://doi.org/10.1007/s00216-0093201-(2)

Andaray AL. 2011. Microplastics in the marine environment. Marine Pollution Bulletin, 62 (3011): 15961605.

https://doi.org/10.1016/j.marpolbul.2 011.05 .030

Aspi, M.B. Malino, \& B.P. Lapanporo. 2013. Analisis data spektrum spektroskopi FT-IR untuk menentukan tingkat oksidasi polianilin. Prima Fisika, 1(2): 92-96. https://doi.org/10.26418/pf.v1i2.306

Baalkhuyur, F.M., E.J.A.B. Dohaish, M.E.A. Elhalwagy, N.M. Alikunhi, A.M. alsuwailem, A. Rostad, D.J. Coker, M.L. Berumen, \& C.M. Duarte. 2018. Microplastic in the gastrointestinal tract of fishes along the Saudi Arabian Red Sea coast. Marine Pollution Bulletin, 131: 407-415. https://doi.org/10.1016/j.marpolbul.2 018.04.040

Boerger, C.M., G.L. Lattin, S.L. Moore, \& C.J. Moore. 2010. Plastic ingestion by planktivorous fishes in the North Pacific Central Gyre. Marine Pollution Bulletin, 60(12): 22752278. https://doi.org/10.1016/j.marpolbul.2 010.08.007

Browne, M.A., S.J. Niven, T.S. Galloway, S.J. Rowland, \& R.C. Thompson. 2013. Microplastic moves pollutants and additives to worms, reducing functions linked to health and biodiversity. Current Biology, 23(23): 2388-2392.

https://doi.org/10.1016/j.cub.2013.10. 012

Claessens, M., S.D. Meester, L.V. Landuyt, K.D. Clerck, \& C.R. Janssen. 2011. Occurrence and distribution of microplastics in marine sediments along the Belgian coats. Marine Pollution Bulletin, 62(10): 21992204. https://doi.org/10.1016/j.marpolbul.2 011.06.030

Cole, M., P. Lindeque, C. Halsband, \& T.S. Galloway. 2011. Microplastics As Contaminants In The Marine Environment: A review. Marine Pollution Bulletin, 62: 2588-2597.

https://doi.org/10.1016/j.marpolbul.2 011.09.025

Firmasyah, F., A. Mustofa, Estradivari, \& A. Damora. 2017. Satu Dekade Pengelolaan Taman Nasional Wakatobi: Keberhasilan dan Tantangan Konservasi Laut. ResearchGate. Jakarta: WWF-ID, 2016. $42 \mathrm{p}$

Giani, D., M. Baini, M. Galli, S. Casini, \& M.C. Fossi. 2019. Microplastics occurrence in edible fish species (Mullus barbatus and Merluccius merluccius) collected in three different geographical sub-aread of the Mediterranean Sea. Marine Pollution Bulletin, 140: 129-137. https://doi.org/10.1016/j.marpolbul.2 019.01 .005

Hidalgo-Ruz, V., L. Gutow, R.C. Thompson, \& M. Thiel. 2012. Microplastics in the Marine Environment: a review of the methods used for identification 
and quantification. Environmental Science and Technology, 46: 30603075.

https://doi.org/10.1021/es2031505

Hirai, H., H. Takada, Y. Ogata, R. Yamashita, K. Mizukawa, M. Saha, C. Kwan, C. Moore, H. Gray, D. Laursen, E.R. Zettler, J.W. Farrington, C.M. Reddy, E.E. Peacock, \& M.W. Ward. 2011. Organic micropollutants in marine plastics debris from the open ocean and remote and urban beaches. Marine Pollution Bulletin, 62(8): 1683-1692.

https://doi.org/10.1016/j.marpolbul.2 011.06 .004

Itano D.G. 2004. A Handbook for the Identification of Yellowfin and Bigeye Tunas In fresh Condition. Pelagic Fisheries Research Programme, Honolulu, Hawaii. p 28.

Iwasaki, S., A. Isobe, S. Kako, K. Uchida, \& T. Tokai. 2017. Fate of microplastics and mesoplastics carried by surface currents and wind waves: A numerical model approach in the Sea of Japan. Marine Pollution Bulletin, 121: 85-96.

https://doi.org/10.1016/j.marpolbul.2 017.05 .057

Kantun, W. \& A. Mallawa. 2016. Biologi Tuna Madidihang (Thunnus albacares). Gadjah Mada University Press : Yogyakarta. 226 p.

Karami, A., A. Golieskardi, Y.B. Ho, V. Larat, \& B. Salamatinia. 2017. Microplastics in eviscerated flesh and excised organs of dried fish. Scientific reports, 7: 5473 .

https://doi.org/10.1038/s41598-01705828-6

Li J., X. Qu., L. Su, W. Zhang, D. Yang, P. Kolandhasamy, D. Li, \& H. Shi. 2016. Microplastics in mussels along the coastal waters of China. Environmental Pollution, 214: 177184. https://doi.org/10.1016/j.envpol.2016. 04.012

Lusher, A.L., M. McHugh, \& R.C. Thompson. 2013. Occurrence of microplastics in the gastrointestinal tract of pelagic and demersal fish from the English Channel. Marine Pollution Bulletin, 67(1-2): 94-99. https://doi.org/10.1016/j.marpolbul.2 012.11 .028

Murphy, F., M. Russell, C. Ewins, \& B. Quinn. 2017. The uptake of macroplastic \& microplastic by demersal \& pelagic fish in the Northeast Atlantic around Scotland. Marine Pollution Bulletin, 122 (1-2). https://doi.org/10.1016/j.marpolbul.2 017.06.073

Nandiyanto, A.B.D., R. Oktiani, \& R. Ragadhita. 2019. How to read and interpret FTIR spectroscope of organic material. Indonesian J. of Science \& Technology, 4(1): 97-118. https://doi.org/10.17509/ijost.v4i1.15 806

Noda, I., A.E. Dowrey, J.L. Haynes, \& C. Marcott. 2007. Group frequency assignments for major infrared bands observed in commo synthetic polymers. Physical Properties of polymers Handbook, pp 395-406.

Nor, N.H.M. \& J.P. Obbard. 2014. Microplastics in Singapore's coastal mangrove ecosystems. Marine Pollution Bulletin, 79(1-2): 278-283. https://doi.org/10.1016/j.marpolbul.2 013.11 .025

Ory, N., C. Chagnon, F. Felix, C. Fernández, J.L. Ferreira, C. Gallardo, O.G. Ordonez, A. Henostroza, E. Laaz, R. Mizraji, H. Mojica, V.M. Haro, L.S. Medina, M. Preciado, P. Sobral, M.A. Urbina, \& M. Thiel. 2018. Low prevalence of microplastic contamination in planktivorous fish species from the southeast Pacific Ocean. Marine Pollution Bulletin, 127: 211-216. 
https://doi.org/10.1016/j.marpolbul.2 017.12 .016

Rochman, C.M., A. Tahir, S. Williams, D,V. Baxa, R. Lam, J. Miller, F.C. Teh, S. Werorilangi, Swee, \& J. Teh. 2015. Anthropogenic debris in seafood: Plastic debris and fibers from textiles in fish and bivalves sold for human consumption. Scientific Reports, 5(1): 14340. https://doi.org/10.1038/srep14340

Rummel, C.D., M.G.J. Loder, N.F. Fricke, T. Lang, E.M. Griebeler, M. Janke, \& G. Gerdts. 2016. Plastic ingestion by pelagic and demersal fish from the North Sea and Baltic Sea. Marine Pollution Bulletin, 102(1): 134-141. https://doi.org/10.1016/j.marpolbul.2 015.11 .043

Santana, M.F.M, L.G. Ascer, M.R. Custodio, F.T. Moreira, \& A. Turra. 2016. Microplastic contamination in natural mussel beds from a Brazilian urbanized coastal region: Rapid evaluation through bioassessment. Marine Pollution Bulletin, 106(1-2): 183-189. https://doi.org/10.1016/j.marpolbul.2 016.02.074

Savoca, S., G. Capillo, M. Mancuso, T. Bottari, R. Crupi, C. Branca, V. Romano, C. Faggio, G.D. Angelo, \& N. Spano. 2019. Microplastic occurrence in the Tyrrhenian waters and in the gastrointestinal tract of two congener species of seabreams. Environmental Toxicology and Pharmacology, 67: 35-41. https://doi.org/10.1016/j.etap.2019.01 .011

Simonds, K. \& C. Page. 2006. Management Measures for Pacific Bigeye Tuna and Western and Central PacificYellowfin Tuna. Amendment 4. Western pacific regional fishery management council. $222 \mathrm{p}$.

Stevenson C. 2011. Plastic debris in the California marine ecosystem: A summary of current research, Solution strategies and data gaps. University of Southern California Sea Grant, California ocean science trust. Oakland (US). 82 p.

Su, L., H. Deng, B. Li, Q. Chen, V. Pettigrove, C. Wu, \& H. Shi. 2019. The occurrence of microplastic in specific organs in commercially caught fishes from coast and estuary area of east China. J. Hazardous Material, 365: 716-724. https://doi.org/10.1016/j.jhazmat.201 8.11 .024

Syakti, A.D. 2017. Microplastics Monitoring in marine Environment. OmniAkuatik, 11(2): 1-6. https://.doi.org/10.20884/1.oa.2017.1 3.2.430

Teuten, E.L., S.J. Rowland, T.S. Galloway, \& R.C. Thompson. 2016. Potential for plastics to transport hydrophobic contaminants. Environ Sci Technol, 41(22): 7759-7764. https://pubs.acs.org/doi/abs/10.1021/e s071737s

Vandermeersch, G., V.C. Lisbeth, J. Colin R, M. Antonia, G. Kit, F. Gabriella, K. Michel J.J, D. Jorge, B. Karen, R. Johan, \& D. Lisa. 2015. A critical view on microplastic quantification in aquatic organisms. Environmental Research, 143: 46-55.

https://doi.org/10.1016/j.envres.2015. 07.016

Verleye, G.A., N.P.G. Roeges, \& M.O.D. Moor. 2001. Easy identification of plastics and rubbers. Rapra Technology Limited, Shrompshire, $174 \mathrm{p}$.

Virsek, K.M., A. Palatinus, S. Koren, M. Peterlin, P. Horvat, \& A. Krzan. 2019. Protocol for microplastics sampling on the sea surface and sample analysis. JoVE, 118: 1-9. https://doi.org/10.3791/55161

Von Moos, N., P.B. Holm, \& A. Kohler. 2012, uptake and effects of 
microplastics on ccell and tissue of the blue mussel Mytilus edulis L. after an experimental exposure. Environ. Sci. Technol, 46(20): 11327-11335. https://doi.org/10.1021/es302332w

Wright, S.L., R.C. Thompson, \& T.S. Galloway. 2013. The physical impacts of microplastics on marine organisms: a review. Environmental Pollution, 178: 483-492. https://doi.org/10.1016/j.envpol.2013. 02.031
Yudhantari, CS., I.G. Hendrawan, \& N.L.P.R. Puspitha. 2019. Kandungan mikroplastik pada saluran pencernaan ikan lemuru protolan (Sardinella lemuru) hasil tangkapan di selat Bali. J. Marine Reseacrh and Technology, 2: $28-52$. https://doi.org/10.24843/JMRT.2019. v02.i02.p10

Submitted: 09 March 2021

Reviewed: 04 April 2021

Accepted : 18 August 2021

\section{FIGURE AND TABEL TITLES}

Figure 1. The type of microplastic fiber / filament found in the study.

Figure 2. Fiber/filament type microplastics: (a) blue, (b) brown, (c) red.

Figure 3. Results of FTIR indentification on fish meat (Thunnus obesus); $x=$ peak, $y=$ intensity.

Table 1. Color and size of fiber / filament type microplastics.

Table 2. Interpretation results of functional groups of fish meat (Thunnus obesus). 
